\title{
Considerações Sobre a História Editorial Recente da Revista
}

\author{
Considerations on the Recent \\ Editorial History of the Periodical \\ Consideraciones Sobre la Historia \\ Editorial Reciente de La Revista
}

William B. Gomes \& Gustavo Gauer

Universidade Federal do Rio Grande do Sul
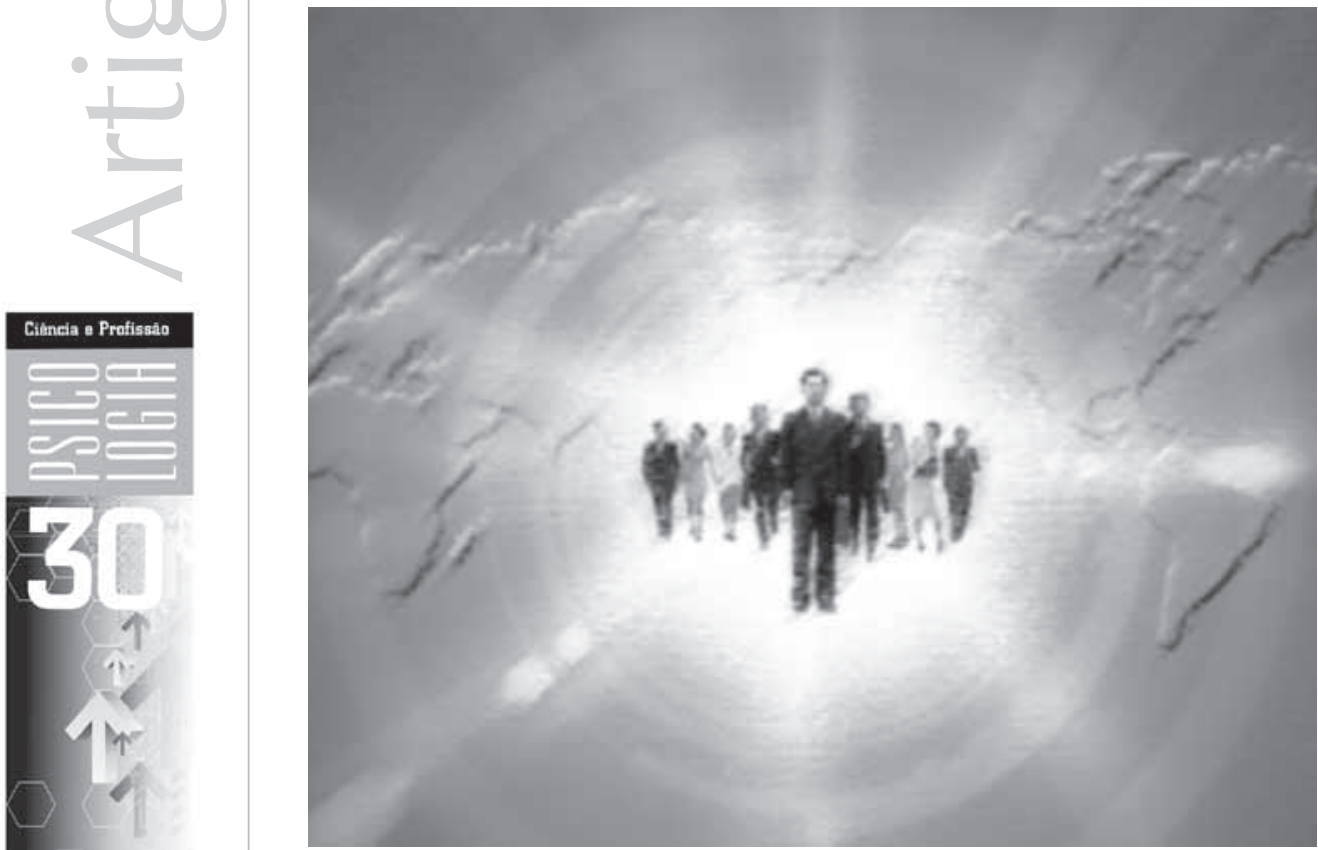
Resumo: Os méritos de Psicologia: Ciência e Profissão (PCP) foram reconhecidos por Campos e Bernardes (2005) em seu registro histórico da revista nos seus primeiros 25 anos. Para as autoras, a revista constituiuse num espaço de excelência para a divulgação de estudos psicológicos brasileiros, e tem contribuído significativamente para o desenvolvimento da Psicologia no Brasil. O presente estudo estendeu a análise histórica de PCP a um período mais recente, estabelecendo uma breve comparação com duas revistas congêneres de outras regiões: American Psychologist e European Psychologist. O artigo conclui que, em períodos recentes, PCP aproxima-se cada vez mais das equivalentes estrangeiras em termos de agenda e das funções potenciais de periódico científico, como uma plataforma para a divulgação internacional dos avanços científicos e profissionais conquistados pelos psicólogos brasileiros.

Palavras-chave: Psicologia. Ciência. Profissão. Revista científica. Publicações.

Abstract: The merits of Psicologia: Ciência e Profissão (PCP) have been recognized by Campos and Bernardes (2005) in their historical record of the journal's first 25 years. For the authors, the journal has provided a unique space for the dissemination of Brazilian psychological studies, and contributed significantly to the development of Psychology in Brazil. The present study extends the analysis to a more recent period and attempts a brief comparison with two similar journals from other regions: American Psychologist and European Psychologist. The article concludes that in recent periods, PCP gets growingly close to its foreign counterparts in terms of an agenda and potential functions as a platform for the international airing of scientific and professional advances obtained by Brazilian psychologists.

Keywords: Psychology. Science. Profession. Journal. Publication.

Resumen: El mérito de Psicología: Ciencia y Profesión (PCP) ha sido reconocido por Campos y Bernardes (2005) en registro histórico ofrecido la ocasión de los primeros 25 años de la revista. Para las autoras, el periódico se caracteriza como un espacio por excelencia para la divulgación de los trabajos de psicólogos brasileños, y contribuye significativamente para la maduración del área. El presente trabajo extiende el análisis para el periodo más reciente y ensaya una breve comparación con dos revistas semejantes, "American Psychologist" y "European Psychologist", concluyendo que PCP ocupa agenda semejante a la de sus congéneres y que está lista para asumir el puesto de portavoz de nuestra ciencia y profesión para la comunidad internacional.

Palabras clave: Psicología. Ciencia. Profesión. Revista científica. Publicaciones.

O Conselho Federal de Psicologia (CFP) foi constituído em 1973, mas o lançamento da revista Psicologia: Ciência e Profissão ocorreu em 1979, último ano da segunda gestão, e sua publicação regular teve início em 1981. Foi um curto intervalo, se comparado à distância entre a criação da American Psychological Association, em 1892, e do periódico American Psychologist, em 1946. O paralelo é pertinente, pois as políticas editoriais das duas revistas são similares, girando em torno dos mesmos propósitos e enfrentando os mesmos desafios na integração de ciência e profissão no grande campo da Psicologia.

O presente artigo é um retrospecto histórico e também uma análise das políticas editoriais recentes da revista Psicologia: Ciência e Profissão, que está alcançando o seu $30^{\circ}$ volume. O artigo está organizado em três partes. Na primeira, dá continuidade ao oportuno estudo de Campos e Bernardes (2005), no qual se destacou a importância da revista no registro da história recente da Psicologia brasileira. Na segunda, visita os periódicos American Psychologist e European Psychologist para comparações de políticas editoriais, o que nos parece apropriado em uma época de reconhecimento e de valorização da cooperação internacional. Na terceira, contrasta as três publicações para diferenciar as suas tendências e para contextualizar as preocupações e as ações 
Em uma segunda fase da revista, de 1984 a 1991, a ênfase editorial já se encontra direcionada para a relevância social dos trabalhos publicados. quanto à internacionalização da Psicologia brasileira como ciência e profissão.

\section{Revista Psicologia: Ciência e Profissão}

O estudo de Campos e Bernardes (2005) acompanhou a trajetória da revista Psicologia: Ciência e Profissão (PCP) de sua inauguração, em 1979, até 2004. A partir da análise de todos os 56 números publicados, as autoras demarcaram quatro períodos na história da revista. Cada uma dessas fases se caracteriza por aspectos da linha editorial do periódico que se modificaram substancialmente ao longo do tempo. Detalharemos, a seguir, os períodos identificados por Campos e Bernardes, com o acréscimo de alguns dados contextuais úteis para a compreensão desses marcos.

No primeiro período da história da revista, de 1979 a 1983, a linha editorial priorizava trabalhos sobre a história da Psicologia e sobre a divulgação da pesquisa psicológica realizada no Brasil. PCP era uma publicação oficial do CFP, destinada a representar o pensamento nacional em Psicologia, e estava encarregada de fornecer informações ao número crescente de psicólogos. No âmbito nacional, trata-se do período da abertura política, nos anos finais do regime militar. $\mathrm{O}$ contexto da Psicologia brasileira na época era peculiar, com um número de profissionais expressivo - 17.000 psicólogos contabilizados no editorial do número inaugural da revista - o que contrastava com uma produção científica praticamente incipiente. Havia carência, à época, de veículos de divulgação para a área. Ademais, os poucos periódicos existentes dificilmente conseguiam efetiva abrangência nacional, tanto na distribuição quanto na representatividade da produção publicada. Nesse período, havia apenas 12 programas de pós-graduação stricto sensu na área da Psicologia. A revista PCP constituía uma iniciativa importante de veiculação de informação para aquele numeroso, e sempre crescente, contingente profissional.

Em uma segunda fase da revista, de 1984 a 1991, a ênfase editorial já se encontra direcionada para a relevância social dos trabalhos publicados. A prioridade era a reflexão sobre o conhecimento e a prática, sobre políticas científicas e profissionais para a área de Psicologia no Brasil. A linha editorial defendia uma revista menos acadêmica e mais flexível. Dentre outras propostas editoriais de PCP no período, destacam-se favorecer a diversidade de abordagens, promover o desenvolvimento de teorias, métodos e técnicas aplicáveis à realidade brasileira, a orientar autores a não utilizar linguagem demasiadamente técnica ou especializada e a não detalhar procedimentos e resultados em suas contribuições à revista. Nesse período, coincidente com a redemocratização do País, PCP passaria a ter menor espaço para a publicação de artigos de pesquisa, voltando-se para a premente veiculação de debates políticos e sociais, que haviam sido tolhidos pelos anos de ditadura. No campo da Psicologia no Brasil, nesse intervalo, ocorriam mudanças e movimentos importantes. Ressaltam-se, entre outros, o crescimento da pós-graduação stricto-sensu em Psicologia, que passou de 12 para 18 programas, a fundação da Associação Nacional de Pesquisa e Pós-Graduação em Psicologia (ANPEPP), em 1983, com a realização do seu primeiro simpósio em 1988. Ressalta-se também a criação de vários periódicos científicos vocacionados, por exemplo, Psicologia: Teoria e Pesquisa (UnB, 1985), Psicologia e Sociedade (ABRAPSO, 1986), Psicologia: Reflexão e Crítica (UFRGS, 1986). Esses movimentos prenunciam e refletem, ao mesmo tempo, o crescimento da produção científica em Psicologia no Brasil. Quanto à profissão, o crescimento já era fato consumado, o que se constata na tiragem da própria revista, que chegava a 75.000 em 1991 (Campos \& Bernardes, 2005). Essa cifra é representativa, 
visto que a revista era distribuída a todos os psicólogos registrados no Sistema Conselhos - embora englobasse também exemplares não destinados aos profissionais.

De 1992 a 1996, a política editorial de PCP apontava uma síntese entre a divulgação de trabalhos socialmente relevantes e o atendimento da demanda espontânea de publicação de artigos científicos e de relatos de experiência profissional. Procurava-se equilibrar as metas do projeto original, que era a divulgação da produção científica nacional, com objetivos mais recentes, como o debate sobre a relevância social do trabalho do psicólogo. Nacionalmente, o período marcava o início de um processo de estabilização política e econômica. O crescimento contínuo do campo profissional nesse período é indicado pela tiragem de PCP, que atingia os 98.000 exemplares no terceiro número de 1996.

Na quarta fase, de 1997 a 2004, a política editorial de PCP priorizaria a veiculação de artigos de pesquisa de primeira linha. $\mathrm{O}$ intuito seria estabelecer a revista como periódico de referência na área, sem perder de vista a preocupação com a relevância social da pesquisa e da atuação. Em 2003, ressaltava-se em editorial a representação da amplitude das áreas de atuação/formação de psicólogos no Brasil e a diversidade dos temas abordados na revista. Nessa época, a revista passa por uma série de adequações técnicas: 1) regularização da periodicidade (1996), 2) constituição de um corpo de consultores adhoc (2000), 3) normatização da publicação de acordo com os critérios externos de qualidade da avaliação CAPES/ANPEPP, 4) indexação em dispositivos como o LILACS (2002) e 5) disponibilização online e com acesso livre pela BVS-PSI (2003). Em 2002, PCP teve a maior tiragem de sua história - 123.000 exemplares impressos - e, em 2003, o acesso passaria a ser prioritariamente online, com relativamente poucos exemplares
(2.000), impressos, a serem distribuídos para instituições. Em 2001, a revista era definida como instrumento de democratização de saberes e fazeres psicológicos produzidos no País e, simultaneamente, como um meio para a aproximação e a congregação dos psicólogos brasileiros (Campos \& Bernardes, 2005). É nesse período (em 2002), que aparece, pela primeira vez a posição de editor da revista, ocupada pelo psicólogo Sergio Antonio da Silva Leite, pertencente ao CRP06 e professor Doutor da Universidade de Campinas (UNICAMP).

\section{Ciência e/ou profissão?}

A descrição das políticas editoriais de PCP por Campos e Bernardes (2005) não esconde as tensões existentes entre a ciência e a profissão. Os dois termos, que não por acaso designam a revista, são alvos frequentes de reformulações na tentativa de encontrar o melhor equilíbrio e o mais claro compromisso entre eles nas políticas editoriais. Isso reflete o papel relevante que a publicação adquire consistentemente, no âmbito do Sistema Conselhos, para a solução dos impasses entre pesquisa e prática. Desse modo, é instrutivo rever como essas tensões aparecem nas diferentes fases da revista.

No primeiro período, a tensão entre ciência e profissão ainda não aparece ou não é mencionada. Considerando que as tensões já ocorriam nos países pioneiros (Hilgard, 1987; Wolfle, 1946), elas ainda não estavam tão presentes entre nós, certamente, pela distância no volume de atividades entre pesquisa e atuação profissional, com vantagem para a última. Em outras palavras, o campo apenas não estaria maduro o suficiente para que a dissociação gerasse tensão e desse lugar ao debate. Essa relativa imaturidade pode refletir-se ainda na atitude perante a produção do conhecimento, em mão única da pesquisa para a prática, ou principalmente da prática para a prática. Apesar de uma 
eventual falta de consciência dessa tensão, os termos ciência e profissão compunham, candidamente, a denominação da revista de Psicologia que teria a maior tiragem em todos os tempos no Brasil. Assim, na primeira fase da história de PCP, ciência e profissão são termos separados presentes no título da publicação, mas a fase seguinte seria de reação a essa condição.

Se, até 1983, não havia consciência das tensões, após a redemocratização, a direção se inverte, priorizando a prática e os debates sociais em detrimento da veiculação de produção acadêmica. Dos períodos seguintes, ressaltamos algumas proposições do problema nas políticas editoriais de PCP. Entre 1992-1996, a revista procurava contemplar a publicação de artigos científicos e de debates de questões relacionadas à relevância social do trabalho dos psicólogos. Ainda nessa época, já se verificam tensões, como entre a orientação que privilegia o debate sobre inserção social do trabalho dos profissionais e a necessidade de dar conta da demanda espontânea pela publicação de artigos científicos temáticos.

Entre 1997 e 2004, a política da revista explicitava o objetivo de equilibrar trabalhos de natureza científica com relatos e discussões das práticas profissionais. O que chama a atenção nessa proposta é que, por mais que o intuito fosse o de articular ciência e profissão, a própria referência aos dois campos permite interpretar uma dicotomia entre os trabalhos que são científicos e os outros, isto é, os relatos e as discussões de práticas. Nesse contraste, a profissão parece responder a algum outro critério que não o da ciência. Claro está que não se trata de uma postura dicotomizada por parte da revista, mas o reflexo da realidade das relações entre ciência e profissão no Brasil e em outros países. Também nessa fase, a publicação dos prêmios monográficos patrocinados pelo Sistema Conselhos de Psicologia era considerada uma oportunidade na divulgação de artigos de alta qualidade sobre temas de grande relevância social.

Os anos 2003 e 2004 marcariam a proposta e a efetivação de uma nova política editorial global por parte do próprio Sistema Conselhos. O projeto de 2003 previa a ampliação do conjunto de publicações, com a criação de uma publicação semestral voltada especificamente para o campo da atuação profissional do psicólogo, a ser intitulada Psicologia: Ciência e Profissão Diálogos, e uma compilação temática anual de artigos científicos. PCP seria mantida como veículo para artigos de pesquisa e relatos de experiência.

\section{Excelência, relevância e alcance de PCP (2004-2010): uma nova fase?}

O fato relevante, ocorrido precisamente ao final do último período historiado por Campos e Bernardes (2005), foi a já citada proposta de segmentação da divulgação científica e profissional por parte do Conselho Federal de Psicologia. O novo projeto previa a criação de uma nova revista, voltada especificamente para interlocuções referentes ao campo profissional, reservando PCP para relatos de pesquisa (artigos científicos), sendo mantido, contudo, o espaço para relatos de experiência. A revista Psicologia: Ciência e Profissão Diálogos estreou em 2004 e tem, até 2010, seis números publicados. Os exemplares são impressos e distribuídos a todos os psicólogos registrados no Sistema Conselhos. As edições são temáticas, e trataram dos seguintes assuntos: Psicoterapia: nas loucuras do desemprego e dos manicômios (abril de 2004, ano 1, no.1); Direitos humanos: subjetividade e inclusão (março de 2005, ano 2, no.2); Os dilemas da avaliação psicológica (dezembro de 2005, ano 2, no.3); Saúde e Psicologia: os desafios teóricos e práticos e as conquistas no cuidado com o sujeito (dezembro de 2006, 
Os editoriais do intervalo de 2005 a 2009 registram claramente os esforços e os embates quanto a escolhas sobre o escopo da revista. ano 3, no.4); Psicologia organizacional e do trabalho: sua evolução, os desafios e os novos rumos (dezembro de 2007, ano 4, no.5), e Álcool e outras drogas (novembro 2009, ano 6 , no.6). A outra publicação idealizada para essa fase, que seria uma compilação anual de artigos de revisão, não se consubstanciou até o momento.

Uma breve análise dos editoriais de PCP no período de 2005 a 2009 indica como evoluíram e se articularam as metas quanto a políticas editoriais e a compromissos da publicação. Os movimentos descritos nessa seção começam efetivamente no último período historiado por Campos e Bernardes (2005), que teve início em 1997, e continuam pelo menos até 2004, ano em que cessa a análise das autoras. Nesse ponto, a interpretação dos acontecimentos e das direções editoriais de PCP permite a postulação de uma nova fase nessa trajetória. O marco do período é a criação da nova revista, voltada para os diálogos profissionais. A característica do período quanto à linha editorial é paradoxal: embora tivesse sido criado um novo espaço específico para a aplicação, PCP não deixou de publicar relatos de experiência. Mais que isso, as transformações de forma e tema dos artigos publicados não parecem ter mudado mais do que mudou a própria área da pesquisa psicológica no País, ou seja, o conteúdo de PCP continua, no mínimo, com a mesma representatividade de períodos anteriores. Contudo, o resultado mais relevante pode ter sido a clareza de se definir a identidade da revista como periódico científico. A nova situação pareceu, por meio do desassombro com relação às tensões, rupturas e desequilíbrios da ciência e da profissão, permitir o crescimento da revista em excelência, elegância, abrangência e representatividade.

Quanto à relevância das discussões sobre as questões sociais prementes, é possível apreender que estas permanecem na ordem do dia dos temas dos artigos publicados. Assim, a trajetória de PCP vem alcançando tamanha maturidade que a revista talvez nunca tenha estado tão próxima das efetivas e críticas articulações, quase sempre problematizadas, mas raramente implementadas em fases anteriores: 1) qualidade versus relevância social, 2) pesquisa versus reflexão, 3) ciência versus profissão.

A revisão da política de publicações dos Conselhos parece ter dado o devido espaço a mudanças relevantes para PCP, sobretudo para a reavaliação de sua missão. Nesse tempo, a revista buscou e conseguiu consolidar-se como periódico científico de referência na veiculação de grande alcance (inclusive internacional) para a produção dos psicólogos brasileiros, sejam pesquisadores, profissionais ou profissionais-pesquisadores. Como se verifica pelo conteúdo dos editoriais, aspectos críticos das políticas de publicação científica ocupam cada vez mais a atenção dos editores: circulação, política de acesso livre, normatização, indexação nacional e internacional, número de citações, indicadores de citações, abrangência temática e de autoria e resultados de avaliação externa (CAPES-ANPEPP, Qualis).

Os editoriais do intervalo de 2005 a 2009 registram claramente os esforços e os embates quanto a escolhas sobre o escopo da revista. Nesse período, passa a contar com um conselho consultivo cujos membros aparecem associados a instituições universitárias. Em 2005, eram reconhecidos os esforços daqueles que:

Batalharam muito para que a revista Psicologia: Ciência e Profissão fosse um espaço qualificado do diálogo entre os que se debruçam sobre o estudo dos muitos construtos psicológicos e os profissionais que se dedicam a várias das atividades possíveis do mundo profissional, com múltiplas práticas e ricas experiências. (PCP, ano 2005, no. 1, p. 3$)$ 
Na mesma época, a diversidade de produção era também destacada quanto ao conteúdo:

Artigos que abordam a miríade de problemas discutidos em nossa área, tanto no plano teórico e empírico como no de experiências profissionais que alguns colegas compartilham com os demais. (PCP, ano 2005, no. 3, p. 335)

Ao longo da trajetória da revista, é digno de registro o empenho em reconhecer o papel de divulgação da produção em pesquisa e aplicação, característico dos periódicos científicos. A avaliação no balanço de 2008, por exemplo, era positiva, tendo em vista que "a revista Psicologia: Ciência e Profissão tem efetivamente contribuído para fazer circular Psicologia por nosso país" (PCP, ano 2008, no. 4, p. 667). Em 2009, continuava a ser ressaltada a missão de divulgação, com "abertura desse espaço editorial aos pesquisadores e profissionais da área com as seções disponíveis que a nossa revista tem para divulgar resultados de pesquisas, reflexões teóricas e relatos de experiências" (PCP, ano 2009, no. 3, p. 435).

\section{Acesso, circulação, novas tecnologias e Qualis}
A acessibilidade e a abrangência da circulação de PCP e as consequências positivas de impacto da revista foram criticamente incrementadas por uma série de iniciativas, todas elas alinhadas com as tendências contemporâneas na política de publicação científica. Além de a revista ter se tornado acessível online a partir de 2004, o período subsequente observou outros avanços fundamentais, com a efetiva indexação no LILACS, PEPSIC, BVS-PSI e, mais recentemente, na SciELO. O processo editorial foi informatizado desde a submissão até a publicação, por meio das ferramentas do Open Journal System (OJS), desde 2008.

A ênfase em divulgação, acesso e circulação, verificada nas políticas editoriais de PCP no período atual, encontrou sólida base nos novos dispositivos disponíveis a partir da informatização. Mais que isso, os efeitos dessa orientação se verificam nos próximos itens desta análise, referentes a excelência e a internacionalização.

Em grande medida por efeito da ampliação substancial do alcance da publicação, PCP verificou, no período iniciado em 2005, indicadores positivos daquilo que pode ser interpretado como o seu impacto. Em 2007, o balanço apresentado no editorial do quarto número do ano constatava que a revista já estava entre as revistas científicas mais citadas da base de dados PEPSIC. Essa situação se confirmava em 2009, com a revista entre as 10 mais citadas, tomando por base o mês de agosto daquele ano.

Esses indicadores preliminares de impacto verificados no número significativo de citações vão ao encontro dos dados de submissões de manuscritos para PCP. A mudança de distribuição para acesso online, com número limitado de exemplares impressos distribuídos prioritariamente a bibliotecas, levou à seguinte consideração em editorial de que houve: "certa retração no número de artigos submetidos à publicação, visto que muitos autores entenderam que a revista não teria mais o potencial de divulgação que possuía até então" (PCP, ano 2007, no. 1, p. 3). No entanto, se conferirmos pelos efeitos negativos, tais apreensões não se confirmaram por sorte e mérito da revista. O acompanhamento dos balanços anuais, publicados nos editoriais a partir de 2007, dá conta de uma tendência consistente de crescimento no número de trabalhos: 84 submissões em 2005, 110 em 2006, 126 em 2007, 167 em 2008 e 210 submissões em 2009.

O crescimento do número de submissões e o fato de se publicarem os balanços 
referentes a esse e a outros dados são evidência suficiente da qualificação de um periódico científico em qualquer área, seja disciplinar, seja geográfica. Mais que isso, os dados de submissões e citações do caso de PCP demonstram uma vez mais o sucesso das políticas de acesso livre e online para periódicos científicos. Apesar da temível redução na tiragem impressa, a qualificação de conteúdo decorrente da seletividade entre um maior número de contribuições e o impacto indicado pela quantidade de citações (além do próprio incremento de submissões) refletem concretamente a crescente relevância do periódico para a área.

O compromisso com a qualidade de produção é verificado nas avaliações de periódicos promovidas por CAPES e ANPEPP, que deram origem ao sistema Qualis. Já no biênio 19982000, PCP alcançara o nível nacional A em Psicologia, mantido durante a vigência do critério original, até 2007. Em 2008, diante da nova proposta de estratificação do Qualis, a revista manifestava em primeira mão apoio à iniciativa:

Considerando que a proposta apresentada visa à qualificação dos periódicos científicos, bem como da pós-graduação brasileira, vale anunciar que a Psicologia: Ciência e Profissão se alinha às novas diretrizes, adotando todas as medidas possíveis para que, em curto e médio prazo, sejam introduzidas nas bases de dados de referência para a Psicologia, além daquelas em que já estamos atualmente. (PCP, ano 2008, no. 2, p. 227)

Desde a implantação dos novos critérios do Qualis 2008, PCP obteve a classificação no estrato B1. Longe de representar depreciação do periódico, essa classificação coloca a revista no terceiro estrato mais elevado entre os oito possíveis, sendo que, nos dois mais altos, constavam em 2008 apenas seis revistas de Psicologia editadas no Brasil. Cumpre destacar que alcançar os próximos estratos será meta realista e próxima, caso PCP a encampe.

\section{Internacionalização}

Em editorial de 2009, uma reflexão importante era colocada sobre os aspectos mais cruciais da missão de PCP como veículo de divulgação. O contexto era o das prioridades de indexação da revista em mecanismos globais ou regionais (PCP, ano 2009, no. 2, p. 211):

Por quem queremos ser lidos? Que impacto causaremos? Que ciência divulgaremos? Quem serão os beneficiados? Não resta dúvida de que pouco adiantará termos leitores dos países norte-hemisferiais se não formos lidos pelos brasileiros e pelos colegas da América Latina.

Naquele mesmo editorial, os editores reiteravam a função de divulgação, ressaltando que acompanhar os debates sobre políticas de editoração científica (como de resto as comissões editoriais vinham fazendo intensamente ao longo do período) era crucial "para que a produção brasileira, em especial a da Psicologia, possa ter seus espaços de divulgação e sua circulação aumentados".

Assim, no período aqui postulado, desde 2005, a preocupação de PCP com a divulgação do seu conteúdo de fato ultrapassa o contexto do alcance nacional, em direção à efetiva integração com o restante da América Latina. Em 2005, a revista já compreendia a relevância do seu papel de facultar acesso livre e online a conhecimento em artigos de alta qualidade não apenas para o Brasil:

A psicologia latino-americana pode contribuir para que haja uma integração efetiva, seja por meio de pesquisas que ampliem o conhecimento sobre os nossos problemas, seja pela convergência de atuação de profissionais que compartilhem das mesmas preocupações. Para tanto, vemos o acesso à informação produzida nos países da região e publicada em revistas, livros, teses e outros meios como o principal caminho a ser percorrido. (PCP, ano 2005 , no. 2 , p. 171) 
No número 3 de 2007, PCP colocava o objetivo de publicar artigos de autores da América Latina, com vistas, sobretudo, ao incentivo do diálogo entre os psicólogos desses diversos países. Embora o número de contribuições tenha permanecido reduzido no período, outras iniciativas continuaram a ser desenvolvidas no sentido de concretizar aquela meta:

Tendo em vista nosso propósito de internacionalização e a necessidade de inclusão em novas bases de dados, de forma a propiciar maior visibilidade às publicações que veiculamos, passamos, a partir deste número, a adotar as normas da American Psychological Association (APA) com as adaptações necessárias à língua portuguesa e a inclusão de colegas latino-americanos no nosso conselho consultivo. (PCP, ano 2008, no. 1, p. 3)

De fato, esses movimentos têm sido mais recentemente refletidos na ampliação real dos horizontes que a missão da revista pode contemplar:

Psicologia: Ciência e Profissão seguirá acompanhando os debates e os esforços para que a produção brasileira, em especial a da Psicologia, possa ter seus espaços de divulgação e sua circulação aumentados. Além disso, buscará contribuir para o desenvolvimento da Psicologia na América Latina, o que exige que as trocas e os debates no campo sejam ampliados. A cada número publicado, reafirmamos nosso compromisso com essa meta (PCP, ano 2009, no. 2, p. 211)

A representatividade de $\mathrm{PCP}$ no cenário da divulgação científica se verifica, nesse período, pela participação em fóruns nacionais e internacionais. Em 2006, era ressaltada a consolidação com a presença de PCP na Associação Brasileira de Editores Científicos de Psicologia (ABECIP), que havia sido fundada nesse mesmo ano. Já em setembro de 2009, a editoria de PCP participava do planejamento da Biblioteca Virtual en Salud - Unión Latinoamericana de Entidades de Psicología (BVS-ULAPSI).
A BVS-ULAPSI já se encontra em pleno funcionamento, atualmente coordenada por equipe brasileira.

\section{Ciência e profissão: publicações congêneres nos EUA e na Europa}

Os mesmos propósitos, questões e transtornos que atravessaram o percurso da brasileira PCP também estavam presentes na história das revistas congêneres American Psychologist e European Psychologist, duas revistas dedicadas ao debate entre ciência e profissão. Uma breve imersão na história dessas publicações apresenta-se como um olhar externo ao desenvolvimento da nossa PCP. Primeiro faremos uma retrospectiva dos 64 anos da American Psychologist e, a seguir, dos 15 anos da European Psychologist.

American Psychologist foi fundada em 1946, ano que marcou a reorganização da American Psychological Association (APA). Diante do crescimento da Psicologia nos Estados Unidos e da diversidade de interesses decorrentes, a APA se reestruturava para contemplar subgrupos específicos, no que viriam a ser as primeiras 18 divisões (por exemplo, clínica, experimental, educacional, organizacional, etc). Atualmente, a APA está organizada em 54 divisões. No artigo inaugural de American Psychologist, Dael Wolfle (1906-2002), primeiro secretário executivo da APA e primeiro editor da revista, ressaltava que a anterior falta de atenção aos interesses específicos por parte da Associação ocasionara a criação da American Association for Applied Psychology (AAAP) e da Society for Psychological Study of Social Issues (SPSSI) (Wolfle, 1946). Sobre os objetivos institucionais da APA, havia o entendimento que a instituição deveria voltar-se para a prática profissional, visto que, até então, se concentrava no avanço da Psicologia como ciência. Isso é demonstrado pela revisão do objetivo institucional, para o "avanço da 
Psicologia como uma ciência, como uma profissão, e como um meio de promover o bem-estar humano" (p. 3). Na verdade, as três primeiras divisões, ainda em 1938, foram bastante identificadas com a profissão: Psicologia clínica, Psicologia educacional e Consulting Psychology (Hilgard, 1987). A fundação de American Psychologist era vista como um reflexo dessas mudanças, já que a revista se destinava originalmente a veicular, com prioridade, informações sobre treinamento, oportunidades de trabalho e organizações em Psicologia, com menor ênfase na divulgação de resultados de pesquisa.

O contexto institucional em que American Psychologist foi inaugurada é o de uma associação científica e profissional de grande abrangência. A APA, sediada em Washington, DC, é a entidade que trata das questões corporativas referentes ao exercício da profissão e da sua regulamentação, da ética científica e profissional, das normas de publicação (inicialmente para a própria área, mas cuja praticidade e atualização sistemática fizeram com que fossem adotadas por várias outras disciplinas), da organização das atividades científicas e do credenciamento e da avaliação dos cursos universitários de formação de psicólogos, entre outras funções. A amplitude de funções da Associação perpassou a trajetória da revista, que se tornou uma referência internacional para questões tanto científicas quanto profissionais e de formação em Psicologia.

American Psychologist iniciou como publicação mensal, e, desde 2004, publica nove números por ano. Atualmente, a revista continua a ser o periódico oficial da APA, e destina-se a divulgar documentos e artigos sobre temas atuais em Psicologia, em ciência e prática da Psicologia, e na contribuição da Psicologia às políticas públicas. A revista publica o relatório anual da Associação, minutas do conselho da APA, informações sobre ética, levantamentos de dados com os membros, mensagens da presidência, estudos históricos, conferências de laureados da própria associação e obituários, entre outros documentos. Todos os anos, a revista publica a lista dos programas de doutorado e de programas de residência credenciados pela entidade, e exerce seu papel de integração e de divulgação para uma categoria profissional de grande diversificação.

A criação de European Psychologist foi inspirada no sucesso de American Psychologist, e coincide com a quarta fase da nossa PCP. Foi fundada por Kurt Pawlik, psicólogo austríaco e professor emérito da Universidade de Hamburgo, apresentando-se como "the English language voice of psychology in Europe". A linha editorial aproxima-se das tendências observadas em PCP, e ocupase da revisão de áreas específicas e de artigos originais, veiculando informações de interesse para a comunidade internacional de Psicologia. Desse modo, a temática dos 15 volumes distribui-se entre história da Psicologia, qualificação profissional, formação em Psicologia, características da profissão em diferentes países europeus e artigos voltados para descobertas científicas em Psicologia e para inovações profissionais.

Atente-se para os passos rumo à consolidação pelo European Psychologist. Lançada em 1996, torna-se órgão oficial da European Federation of Psychologists' Association (EFPA), em 2001, mas preservando a autonomia editorial. A EFPA é um fórum de 35 associações nacionais de Psicologia, que congrega atualmente cerca de 250.000 psicólogos. A Federação tem como metas a integração de prática e pesquisa e a promoção de uma disciplina integrada da Psicologia. Em 2002, European Psychologist (EA) torna-se disponível online, celebrando a sua consolidação em 2005, quando recebe, pela primeira vez, o fator de impacto de 0,691 fornecido pelo Information Science Institute (ISI). Fator de impacto é a medida utilizada 
para estimar a frequência com que artigos publicados em um jornal têm sido citados em determinado ano. Para tanto, soma-se o número de citações de artigos dos dois últimos anos de uma revista e divide-se esse número pelo total do número de artigos publicados no mesmo período. É um indicador já utilizado para efeito de Qualis em muitas áreas do conhecimento no Brasil, como a Física, a genética e mesmo a Medicina. Em 2009, o fator de impacto da EA foi 1,481, e a revista, classificada como multidisciplinar no grande campo da Psicologia, competia com gigantes, indicados pelo impacto, como Annual Review of Psychology (22,750), Psychological Bulletin (12,854), Psychological Review $(9,082)$ e American Psychologist $(6,537)$. A título de comparação, a revista brasileira com maior fator de impacto é Psicologia: Reflexão e Crítica, com 0,150 , ressaltando que se trata de publicação escrita predominantemente em português, mas que atualmente incentiva a publicação de artigos em inglês.

\section{Contrastes e convergências entre as três publicações}

Em 1983, o primeiro autor deste artigo retornava ao País após doutoramento no exterior. Em vez de se dedicar de imediato à transformação da tese em artigos, preferiu preparar e submeter um texto a PCP com sugestões de articulações editoriais para os periódicos nacionais em Psicologia. A análise preocupava-se com a indefinição temática das revistas existentes na época e defendia uma função especial e representativa para PCP, como porta-voz da Psicologia brasileira. O texto não foi aceito, talvez por conter proposições que estavam à frente do tempo, talvez por outros problemas. Seja como for, o documento teve decorrências importantes para as políticas editoriais em Psicologia no Brasil. Uma delas foi a criação de Psicologia: Reflexão e Crítica, periódico brasileiro melhor avaliado na área em 2009 (Qualis A1); outra foi a realização de um grupo de trabalho temporário na ANPEPP para discutir e propor sugestões para a área, como um projeto para a indexação dedicado às revistas psicológicas brasileiras (Gomes \& Rosa, 1992). Passados esses anos e depois de tantos avanços, a indexação de fato ocorreu, com a criação da Biblioteca Virtual da Saúde, em 1997, e temos uma Associação Brasileira de Editores Científicos de Psicologia (ABECIP), mas a tematização das revistas ainda é tímida. Boa parte dessas revistas continua sem clareza de missão e com entendimentos ambíguos do caráter generalista, o que prejudica a avaliação de pares por falta de identidade editorial. Uma evidência dessa triste realidade está na ambiguidade e na repetição do mesmo título por periódicos de diferentes instituições. Contudo, já desponta um número crescente de revistas temáticas, algumas em inglês, e PCP realiza a expectativa do velho texto de 1983 de assumir a sua posição privilegiada no campo editorial da Psicologia: uma revista que fale para toda a categoria e também para estudantes e estudiosos.

Os artigos submetidos a publicação atendem muitas demandas: 1) aqueles artigos mais identificados com os interesses e propósitos do autor do que com as expectativas da comunidade (p. ex., revisões de literatura burocráticas, pobres em estilo, sistematização e abrangência); 2) aqueles artigos que refletem estudos de rotina e atualização de uma especialidade e que poderiam estar em uma revista temática; 3) aqueles artigos que não vão além de exercícios reflexivos, aliás forma muito frequente em nossa literatura especializada; 4) aqueles artigos que tratam do estado da arte de um tema, de personagens ou episódios da História; 5) aqueles artigos que abordam grandes debates disciplinares e interdisciplinares, e 6) aqueles artigos que realmente inovam na pesquisa e na prática. Por tal critério, pode-se constatar que essa diversidade temática, com seus aspectos fortes e fracos, está tanto no American Psychologist quanto no European Psychologist, embora a ocorrência de textos voltados para os grandes debates, para atualizações e para a inovação sejam expressivos. A seguir, serão ressaltados 
temas que retratam fortemente a agenda temática de uma publicação de interesse geral da categoria; em primeiro lugar, o American Psychologist, passando logo depois para o European Psychologist, para concluir com PCP.

Por exemplo, como temas de interesse geral no American Psychologist, tratando das questões da ciência, da categoria, das políticas públicas e da interdisciplinaridade, podem ser mencionados, indicando-se o ano de publicação: saúde mental (1996), educação básica (1997), inteligência (1997), teorização em Psicologia (1998), diversificação em Psicologia (1999), problemas da ênfase exagerada em publicação (2000), diversidade sociopolítica (2000), globalização (2002), masculinidade (2003), pobreza e infância (2004), avaliação psicológica pela internet (2004), a virtude do multiculturalismo (2006) e orientação para trabalho psicológico com meninas e mulheres (2009). A ênfase, no European Psychologist, está muito em torno da formação profissional, certamente refletindo as grandes reformas por que passou o ensino superior: padrão de qualidade para as competências e habilidades de psicólogos (1986), ensino de Psicologia (1997), profissionalização (1999), Psicologia evolucionista (2000), moderno interacionismo (2001), genética e Psicologia (2001), qualificações para psicólogos europeus (2002), formação de Doutores em Psicologia (2003), desenvolvimento humano e bem-estar social (2005) e Psicologia da paz (2010). O mesmo olhar para PCP vai nos levar a tópicos convergentes: nós, psicólogos brasileiros, e a cidadania (1996), aconselhamento genético (1996), avaliação neuropsicológica (1966), formação e exercício profissional (1997), trabalho, tempo e subjetividade (1998), homossexualidade (1999), globalização (1999), meninos de rua (2000), masculinidade (2000), inserção do psicólogo no programa governamental para a família (2002), neopentecostalismo (2004), violência contra as mulheres (2006), reforma psiquiátrica e inclusão social (2009), formação em Psicologia no Brasil (2009) e desastres aéreos (2009). É sempre uma temeridade recolher, por limites de espaço, um número restrito de temas. No entanto, essa comparação breve e superficial é suficiente para mostrar que PCP está se expressando na mesma linguagem de suas congêneres, preparando-se para se dirigir ao mundo em nome dos psicólogos brasileiros, sendo o nosso Brazilian Psychologist. Uma seleção dos artigos que falam de nossas grandes articulações e inovações, e dos grandes debates nacionais, bem que poderia compor uma publicação em inglês, quem sabe intitulada Brazilian Psychologist.

\section{Considerações finais}

O mérito de PCP foi ressaltado por Campos e Bernardes (2005) ao contemplarem os primeiros 25 anos da revista: "um espaço, por excelência, de divulgação dos trabalhos de psicólogos brasileiros, o periódico contribuiu significativamente para o amadurecimento dessa área do saber". O presente trabalho, com base no estudo daquelas autoras e no acompanhamento do período mais recente da história da revista, toma a liberdade de apenas expandir aquela proposição. Psicologia: Ciência e Profissão consolidou-se em 30 anos como um espaço de excelência, relevância e alcance na divulgação da produção nacional em Psicologia. Com efeito, hoje já contamos com 64 cursos de pós-graduação stricto sensu, mais de 400 cursos de graduação, e já somos uma comunidade de mais de 160.000 psicólogos. A excelência é estabelecida em uma política editorial que responde a critérios estritos de avaliação da produção científica. A relevância na divulgação do trabalho dos psicólogos brasileiros é confirmada pela significativa quantidade de citações que a revista vem alcançando em um universo cada vez mais povoado de periódicos científicos. O alcance da divulgação confirma-se na efetiva ampliação do acesso ao conteúdo veiculado: livre, integralmente online e indexado nacional e internacionalmente. Essa trajetória evidencia que a revista não apenas contribuiu para o amadurecimento da área mas também amadureceu com ela. 


\section{William B. Gomes}

Doutor em Higher Education pela Southern Illinois University - Carbondale, professor de Historia da Psicologia e Fenomenologia Experimental na Universidade Federal do Rio Grande do Sul, Rio Grande do Sul - RS - Brasil Email: gomesw@ufrgs.br

\section{Gustavo Gauer}

Doutor, professor adjunto Instituto de Psicologia - Universidade Federal do Rio Grande do Sul, Rio Grande do Sul - RS - Brasil

E-mail: gusgau@gmail.com

*Endereço para envio de correspondência:

Universidade Federal do Rio Grande do Sul - Instituto de Psicologia

Rua Ramiro Barcelos, 2600, sala 123, Porto Alegre, RS - Brasil CEP 90035-003 
Campos, R. H. F., \& Bernardes, L. H. G. (2005). A revista Psicologia: Ciência e Profissão: um registro da história recente da psicologia brasileira. Psicologia: Ciência e Profissão, 25(4), 508-525.

Hilgard, E. (1987). Psychology in America. San Diego: Harcourt.

Gomes, W. B., \& Rosa, T. (Eds.). (1992). Divulgação de pesquisas em Psicologia no Brasil (Cadernos ANPEPP). São Bernardo do Campo: IME.
Wolfle, D. (1946). The reorganized American Psychological Association. American Psychologist, 1, 3-6. 